\title{
Coronavirus Disease 2019 Pandemic and Tuberculosis Control: Possibilities of Joint Action
}

\author{
Saurabh RamBihariLal Shrivastava, Prateek Saurabh Shrivastava \\ Department of Community Medicine, Shri Sathya Sai Medical College and Research Institute, Sri Balaji Vidyapeeth - Deemed to be University, Chengalpet, \\ Tamil Nadu, India
}

\section{INTRODUCTION}

The impact of coronavirus disease 2019 (COVID-19) pandemic has extended way beyond the health sector alone, and it has resulted in disruption of the social life and economic growth of the nation and has even instilled a wide range of fears and uncertainties among both the health authorities and the general community. ${ }^{[1]}$ As on December 13, 2020, a total of 70 million people have been diagnosed with the infection, of which 1.6 million people have succumbed to the disease-related complications. ${ }^{[2]}$ The severity of the disease can be just understood by the fact that 219 nations and territories have reported COVID-19 cases, and there is a potential risk of second wave in each and every nation. ${ }^{[2]}$ All these facts are indeed a great cause of public health concern and justify the fact that whatever we are doing as of now is not enough and the efforts need to be more intensive and accelerated if we want to end this pandemic in the near future. ${ }^{[1,2]}$

\section{Tuberculosis and Coronavirus Disease 2019}

On the other hand, at the global level, we are also fighting against tuberculosis (TB), which is another infectious disease that has left the public health sector to adopt innovative strategies for its containment. Despite the fact that the disease is being known for many decades and with the availability of curative drugs (in contrast, COVID-19 is a novel infection with no therapeutic option available as of now), the disease accounted for 10 million cases and 1.5 million deaths in a single year. ${ }^{[1,3]}$ Thus, the case fatality rate of TB stands at 15\%, which is way higher that COVID-19, and it is important to note that, in these alarming global estimates of TB, drug-resistant forms of TB have not been included. ${ }^{[2,3]}$ Epidemiological estimates of COVID-19 have shown that the disease is not very frequent or severe among children. However, that is not true in the case of TB and the estimates suggest that, in 2019, 1.1 million children were diagnosed with the infection, of which 0.2 million lost their lives. ${ }^{[1-3]}$

\begin{tabular}{|l|l|}
\hline \multicolumn{3}{|c|}{ Access this article online } \\
\hline Quick Response Code: & Website: \\
\hline & www.ijrc.in \\
\hline & \\
\hline
\end{tabular}

\section{Strengthening Infection Control Services: Joint APPROACH}

As the battle against the COVID-19 intensifies globally, it is a must that all the essential health services pertaining to the control of TB and other public health priorities should not be ignored ${ }^{[4]}$ This becomes an indispensable need as reallocation of all resources toward COVID-19 will bring about a rapid rise in the incidence and death rates due to these infections, which will further complicate the entire health scenario. ${ }^{[4]}$ The best way to approach both the infectious diseases is to carry out joint activities as both the diseases will require innovative and community-centered strategies for their containment. ${ }^{[4,5]}$

The option of carrying out combined activities is very much on the cards as the symptoms (viz., cough, fever, and dyspnea) and mode of transmission (close contact) of both the diseases are quite similar. ${ }^{[5]}$ This will not only aid us in the better containment of both the infectious diseases but will also help the public health authorities to save a lot of resources by avoiding duplication of work, especially in the current situation, wherein the healthcare delivery system has already been overwhelmed..$^{[3-5]}$ However, as the available evidence has suggested that the treatment outcome of COVID-19 in people with pre-existing diseases is not encouraging, it is ideal that TB patients should take all precautions to prevent the acquisition of COVID-19 and

Address for correspondence: Dr. Saurabh RamBihariLal Shrivastava, Department of Community Medicine, Shri Sathya Sai Medical College and Research Institute, Sri Balaji Vidyapeeth - Deemed to be University, Tiruporur - Guduvancherry Main Road, Ammapettai, Nellikuppam, Chengalpet - 603 108, Tamil Nadu, India. E-mail: drshrishri2008@gmail.com

This is an open access journal, and articles are distributed under the terms of the Creative Commons Attribution-NonCommercial-ShareAlike 4.0 License, which allows others to remix, tweak, and build upon the work non-commercially, as long as appropriate credit is given and the new creations are licensed under the identical terms.

For reprints contact: WKHLRPMedknow_reprints@wolterskluwer.com

How to cite this article: Shrivastava SR, Shrivastava PS. Coronavirus disease 2019 pandemic and tuberculosis control: Possibilities of joint action. Indian J Respir Care 2021;10:158-9.

Received: $18-11-2020$

Accepted: $28-12-2020$

Revised: $19-12-2020$ Published: $31-01-2021$ 
not falter in any aspect with regard to ongoing TB treatment adherence. ${ }^{[4,5]}$

\section{Role of Public Health Authorities}

In these testing times, the public health authorities should continue to support the delivery of essential TB-related services and educate the people about the importance of cough etiquettes, isolation, and other infection prevention measures as it will be applicable to COVID-19 as well..$^{[3,6]}$ It will be ideal that all symptomatic patients should be tested for both the diseases, and the existing framework of TB sample transportation can be utilized even for COVID-19. ${ }^{[5]}$ The outreach programme staff should aim to contact tracing for both the diseases using their expertise. ${ }^{[4]}$ However, for better communication and timely updates, digital technologies or risk communication mechanism can be employed and it will help control both the diseases. ${ }^{[5,6]}$ Further, steps should be taken to improve the availability of human resources (involving retired doctors), who will play an instrumental role in the early detection and treatment of both the life-threatening infections.

\section{Other INTERVENTIONS}

It is quite obvious that we will not succeed in our battle against the disease, if the delivered services are not properly planned and supported well with uninterrupted supply of logistics (viz., personal protective equipment, anti-TB drugs, and hand hygiene-related materials), and this will essentially require better inventory control and keeping things with us based on the disease projections. ${ }^{[3-6]}$ At the same time, it is extremely important to ensure that steps are taken to avoid stigmatization of the infected population groups. If people hide their illnesses, they will infect many more of their contacts, and then, it will become extremely difficult to identify and treat each and every one of them..$^{[1,3,5,6]}$

\section{ConcLusion}

Both COVID-19 and TB are public health priorities and linked with high incidence and mortality rates, if left undiagnosed and untreated. This calls for the need to unite all the available resources, including workforce, and fight together against the disease with a sole aim to benefit humankind.

\section{Financial support and sponsorship}

Nil.

\section{Conflicts of interest}

There are no conflicts of interest.

\section{ReFERENCES}

1. Ward MP, Li X, Tian K. Novel coronavirus 2019, an emerging public health emergency. Transbound Emerg Dis 2020;67:469-70.

2. World Health Organization. Weekly Operational Update on COVID-19 - 15 December 2020. World Health Organization; 2020. Available from: https://www.who.int/publications $/ \mathrm{m} / \mathrm{item} /$ weekly-epidemiological-update---15-december-2020. [Last accessed on 2020 Dec 18].

3. World Health Organization. Tuberculosis - Key Facts. World Health Organization; 2020. Available from: https://www.who.int/news-room/ fact-sheets/detail/tuberculosis. [Last accessed on 2020 Nov 18].

4. World Health Organization. Ensuring Continuity of TB Services during the COVID-19 Pandemic. World Health Organization; 2020. Available from: https://www.who.int/news-room/detail/24-03-2020-ensuring-con tinuity-of-tb-services-during-the-covid-19-pandemic. [Last accessed on 2020 Nov 18].

5. World Health Organization. World Health Organization (WHO) Information Note-Tuberculosis and COVID-19. Geneva: WHO Press; 2020. p. 1-4.

6. World Health Organization. 2019 Novel Coronavirus (2019-nCoV): Strategic Preparedness and Response Plan. Geneva: WHO Press; 2020. p. 1-20. 